\title{
Da poesia à prosa: a influência da releitura de Baudelaire e Rimbaud na pós-poesia de Jean-Marie Gleize
}

\section{From poetry to prose: the influence of rereading Baudelaire and Rimbaud in postpoetry from Jean-Marie Gleize}

\author{
Erica Milaneze \\ Universidade Estadual de Campinas (Unicamp), Campinas, São Paulo, Brasil. \\ erica.milaneze@gmail.com
}

Resumo: No cenário da poesia francesa contemporânea, a pós-poesia representa a busca por novas formas experimentais que se constituem por meio de uma escrita em prosa literal, que tenta efetuar uma "saída" dos modelos tradicionais da poesia, encontrando em Jean-Marie Gleize seu grande animador e teórico. Os diversos textos pós-poéticos gleizeanos são representativos, particularmente, Les chiens noirs de la prose (1999), desta vertente experimental que encontra suas origens na leitura da modernidade poética, destacando-se seu diálogo com as obras de Charles Baudelaire e de Arthur Rimbaud.

Palavras-chave: poesia contemporânea; poesia francesa; pós-poesia; Gleize; Baudelaire; Rimbaud.

Abstract: In the literary scene of contemporary French poetry, the postpoetry represents a search for new experimental forms that constitute by means of a written literal prose, that tries to make an "exit" of the traditional models of poetry, found into Jean-Marie Gleize his great animator theoretical. The various postpoetic texts gleizean are representative particularly, Les chiens noirs de la prose (1999), this experimental poetry, that finds its origins in the reading of modernity poetry, standing out its dialogue with the work of Charles Baudelaire and Arthur Rimbaud.

Keywords: contemporary poetry; French poetry; Postpoetry; Gleize; Baudelaire; Rimbaud. 
Recebido em 31 de dezembro de 2014

Aprovado em 19 de abril de 2015

Em meio à diversidade de autores e de estilos de escrita apresentada pela poesia francesa publicada nos últimos trinta anos, a pós-poesia, ou prosa em prosa(s), tem suscitado inúmeros debates e críticas acerca dos rumos trilhados pela poesia contemporânea. A póspoesia propõe a criação de uma prosa experimental caracterizada pela literalidade e por processos de montagem, que resultam em objetos ou dispositivos verbais que se situam fora do âmbito da poesia, atuando como uma reação ao processo de recuperação e de renovação do lirismo, iniciado a partir dos anos de 1980, na França. Dando sequência às tendências neo-vanguardistas e à "modernidade negativa" dos anos de 1960 e 1970, a pós-poesia encontra os subsídios para sua constituição na modernidade poética, notadamente, na releitura das obras de Charles Baudelaire e de Arthur Rimbaud, efetuada por seu grande animador, teórico e divulgador dentro e fora do contexto literário francês, o póspoeta Jean-Marie Gleize (1946), cujas obras e ensaios críticos são representativos desta vertente poética, de modo particular, a prosa em prosas Les chiens noirs de la prose (1999).

A pós-poesia se pauta pela literalidade que se define, segundo Gleize (2009, p.81), pela reflexividade, ou seja, o enunciado literal é aquele que diz o que faz; e pela intenção realista por meio da qual o enunciado diz o que verdadeiramente acontece, o que determina um tratamento negativo e crítico de tudo o que faz écran e imagem. No entanto, Gleize (1996a, s.p.) adverte que "la 'littéralité' n'existe pas. Ça n'est qu'une postulation, une intention [...] S'il n'y a pas d'énoncé littéral à proprement dire, mais des énoncés pouvant tendre à une utopique littéralité, alors il n'y a pas de "poésie littérale". Conclui-se que o projeto pós-poético gleizeano se apoia na proposição ou na hipótese de construção de enunciados literais, pois a musicalidade e as imagens são inerentes à língua, sendo impossível atingir uma neutralidade completa. Consequentemente, Gleize descarta a possibilidade de uma poesia literal e, assim, a pós-poesia se encaminha para a prosa. Um dos principais pressupostos da pós-poesia é permanecer o mais próximo possível do que o autor denomina "altitude zero", ou melhor, da formulação de um enunciado plano que tenta transmitir a realidade em toda a sua verdade, de maneira a atingir a "nudez integral" ou o "nu desnudado". 
No ensaio "Les chiens s'approchent, et s'éloignent" (2009), Gleize recupera duas figuras criadas por Baudelaire para representar o poeta, vinculando-as às concepções formais poéticas, a saber, o gato, figura mítica que se relaciona aos aspectos líricos presentes em Les Fleurs $d u$ mal, e o cão, que se refere ao prosaísmo dos poemas em prosa de Spleen de Paris - Petits poèmes en prose. Conforme sua interpretação, o gato e o cão representam um percurso de passagem da poesia, do "canto das flores" para a dissonância e a divagação da prosa. Assim, o autor toma partido pelo cão em detrimento do gato, do "pauvre chien, exténué mais allant, cherchant, avançant à la rencontre de la rencontre" por entre as "ravines sinueuses des immenses villes" (GLEIZE, 2009, p.192), que se torna o 'condutor' de sua decisão de declarar-se a favor da prosa que figura o cenário da perda de auréola do poeta e sua submissão à realidade, ao horror e à desolação da vida, como denota o poema em prosa "Les bons chiens":

J'invoque la muse familière, la citadine, la vivante, pour qu'elle m'aide à chanter les bons chiens, les pauvres chiens, les chiens crottés, ceux-là que chacun écarte comme pestiférés et pouilleux, excepté le pauvre, dont ils sont les associés, et le poète, qui les regarde d'un œil fraternel.[...] Je chante les chiens calamiteux, soit ceux qui errent, solitaires, dans les ravines sinueuses des immenses villes [...]. (BAUDELAIRE, 1998, p.140-141; GLEIZE, 2009, p.196, grifos nossos)

Interpretando o poema pelo viés metapoético, Gleize aponta o rompimento com a poesia e a busca de uma escrita prosaica e do prosaico que traduza a realidade circunstancial que os cães captam durante seu deslocamento. Tal escrita relaciona-se ao anseio exposto por Baudelaire na carta prefácio de Spleen de Paris que define a construção formal de seus poemas em prosa:

Quel est celui de nous qui n'a pas, dans ses jours d'ambition, rêvé le miracle d'une prose poétique, musicale sans rythme et sans rime, assez souple et assez heurtée pour s'adapter aux mouvements lyriques de l'âme, aux ondulations de la rêverie, aux soubresauts de la conscience? (BAUDELAIRE, 1998, p.26, grifos nossos)

Ao ler a frase "uma frase poética, musical sem ritmo e sem rima", Gleize considera uma contradição entre poético/musical e sem ritmo/sem 
rima, porque a musicalidade que caracteriza a poesia provém das repetições causadas pelo ritmo e pela rima: uma prosa não ritmada e não rimada se transforma em uma 'simples' prosa, desprovida de prosódia, de imagens, de comparações e de metáforas; por isto, o pós-poeta reescreve a frase baudelairiana: “qui de nous n'a pas rêvé d'une prose? D’une prose non re-poétisée par l'image, sans comparaison ni métaphore, d'une prose 'très prose', comme dit Flaubert dans une lettre à Louise Colet, d'une 'prose en proses', comme je suggère qu'on dise [...]" (GLEIZE, 1996b, s.p., grifo nosso). Desta forma, efetua uma leitura da colocação baudelairiana do ponto de vista de seu projeto pós-poético, como já denota a substituição de uma "prosa poética" por uma "prose particulière", "sans rythme" e "sans rime" (GLEIZE, 2009, p.196), pois sua análise se direciona para a recusa das formas de sublimação estilística e de re-poetização idealizante. Embora não negue o projeto baudelairiano como a expressão de uma formulação do poema em prosa - porque afirma que Baudelaire "chemine des 'merveilleux nuages' et de la postulation d'une 'beauté immortelle' (trait d'union avec les Fleurs $d u$ Mal, pour un poète qui tire vers le haut, le ciel l'azur, par-delà, etc. ), à ce 'rendu au sol', aux sinueuses ravines de la circulation urbaine" (GLEIZE, 2009, p.196-197) - sua reinterpretação, entretanto, mostra que existe um outro modelo inscrito simultaneamente no texto, que remete a um "contra-modelo" ao poema em prosa stricto sensu, que nomeia de pós-poesia. O poeta moderno já fornece, a seu ver, uma proposta de escrita experimental mais próxima "de ce que nous attendons aujourd'hui d'une écriture critique objective, 'objectivante', après la 'poésie"' (GLEIZE, 2009, p.195-196), situando-se como um precursor da pós-poesia, ao propor uma linguagem experimental em prosa que rompe com os modelos até então considerados pertencentes à poesia, indo inclusive contra e além do próprio modelo que cria para o poema em prosa, conforme se depreende de sua interpretação: "Baudelaire, d'une certaine façon, contre Baudelaire" (GLEIZE, 2009, p.197). Os cães negros da prosa são, então, os primos dos “bons e pobres cães", uma vez que "témoignent d'une sortie formelle hors du moule et du manège. De l'effort de la poésie contre elle-même". (GLEIZE, 2009, p.198).

A escrita literal da pós-poesia gleizeana parte da passagem ou da transformação da estrutura formal dos versos para o formato da prosa, abandonando a musicalidade das frases e, assim, a estrutura sonora repetitiva que ecoa de uma frase para a outra para criar um sentido a favor do "quarto real" ou do "primeiro quarto" - o que remete ao poema 
em prosa "La chambre double", de Spleen de Paris -, onde prevalece a pobreza do literal que tenta transmitir uma imagem do real distanciada do metafórico.

Se a passagem do canto das flores para a perambulação das prosas representa para Gleize o encaminhamento da poesia para a prosa, o mesmo percurso é oferecido pela análise das obras de Rimbaud: "[...] avec Rimbaud la poésie prend le chemin de la prose, se met en chemin vers la prose, sur les sentiers de banlieue, les yeux tournés vers le sol, les flaques et les très petits poissons" (GLEIZE, 2009, p.123, grifo nosso). Tendo também como suporte a leitura de Rimbaud, Gleize toma o rumo da prosa, de uma prosa literal e réeliste que, por meio de um extremismo experimental, lido nas obras rimbaudianas, mostra o real, o mundo real tal qual se expõe quando o poeta abandona a transcendência e a sublimação linguageiras. Como o jovem do poema "Ma bohème", Gleize tira os elásticos das botinas à beira do caminho e adota, como sintetiza sua frase-fórmula "un pied contre son [sic] coeur", uma atitude performática, em que o órgão do sentimento é substituído por um dos membros do movimento, o movimento retilíneo, linear e aberto da prosa em oposição ao círculo fechado descrito pelo poema.

Em estreita ligação com a reflexão metapoética de seu projeto estético, Gleize publica Les chiens de la prose (1999) que considera uma tentativa de "prose en prose après la poésie" (GLEIZE, 2009, p.198), cujo ponto de partida é a questão “Où vont les chiens?”, feita por Baudelaire em "Les bons chiens", copiada de um folheto de jornal, espaço da diversidade e da prosa mais trivial e cotidiana. O pós-poeta a recopia, por sua vez, do poema baudelairiano para uma das prosas de Les chiens noirs de la prose:

Où vont les chiens?

Où vont les chiens, dites-vous.

Où vont-ils [...] (GLEIZE, 1999, p.79)

Esta indagação encontra sua resposta no itinerário dos "bons cães" baudelairianos que "erram pelas ravinas sinuosas das grandes cidades". De fato, Gleize aproxima o passado literário ao presente quando situa o poeta no espaço contemporâneo:

A questão é proposta por Baudelaire na última de suas "prosas" em poema por uma poesia adaptada às "ravinas sinuosas" das cidades. E é aí que estamos, é aí que ainda 
estamos. No extremo final do século 20, entre muros cada vez mais altos, falésias à pic, e nós ao fundo. Trata-se de re-encantar o mundo? (GLEIZE, 2004b, p. 38, grifos nossos)

O percurso dos cães baudelairianos serve de justificativa para a escolha gleizeana de uma prosa que traduz a sociedade midiática e tecnológica atual - assim como Baudelaire criou a forma do poema em prosa para dizer a sociedade de sua época -, pautada na literalidade e na realidade integral, porque acredita que não é mais possível idealizar ou sublimar o mundo.

$\mathrm{Na}$ esteira de Rimbaud, Gleize traça a relação entre o poeta, a poesia e a sociedade nas primeiras páginas do ensaio Sorties (2009), em que cita o poema em prosa "Ville", de Illuminations, interpretando-o e vinculando-o ao contexto social e poético contemporâneo:

Deux phrases de Rimbaud, dans une de ses Illuminations (celle qui s'intitule Ville - et c'est là, ici, en effet, rues et passages, métros et voies rapides, échangeurs, ascenseurs, écrans, trous béants, périphériques, où que nous soyons, où que nous pensions être, que notre vie se "déroule"): Ici vous ne signaleriez les traces d'aucun monument de superstition. La morale et la langue sont réduites à leur plus simple expression, enfin! (GLEIZE, 2009, p. 23, grifos do autor)

$\mathrm{Na}$ confluência do presente com o passado literário, os dêiticos là e ici aproximam o contexto do poema do passado ao da pós-poesia contemporânea: é là na cidade da segunda metade do século XIX, "une metrópole crue moderne" (RIMBAUD, 1984, p.171), que se refere à cidade de Londres onde Rimbaud permanece com Verlaine entre $1872 \mathrm{e}$ 1873, mas é também ici, nas grandes metrópoles contemporâneas, entre suas ruas, metrôs, elevadores e écrans etc., que se situa o pós-poeta "cão negro da prosa". Se Gleize aponta que é lá "nas ravinas sinuosas" que os poetas do extremo final do século XX ainda estão, encontram-se também em "uma metrópole que se acredita moderna" ou contemporânea. A modernidade e o contemporâneo se cruzam, portanto, aos olhos do autor, quanto ao lugar e à função do poeta frente a seu contexto social.

O pós-poeta reconfigura, então, o espaço por onde se deslocam os cães: "nous ne circulons plus 'dans les ravines sinueuses des immenses villes' mais entourés d'écrans", o real na sociedade midiática se mostra 
uma imagem do real, a realidade é "tele-real" (GLEIZE, 2009, p.201), sendo a midiatização um dos principais problemas apontados por Gleize que a sociedade contemporânea enfrenta; daí, a tentativa de adequar sua proposta estética ao contexto do extremo contemporâneo, influenciado por Baudelaire que, conforme sua leitura, convida a procurar as formas de uma "prosa particular", ligada, nos dias atuais, "aux nouvelles formes de sensibilité et de conscience engendrée par les conditions concrètes de la vie matérielle dans les nouvelles agglomérations urbaines" (GLEIZE, 2009, p.196). Todavia, assume uma postura crítica ao trabalhar sobre, com e contra os formatos que a midiatização do real impõe, separando o homem da realidade integral. A poética gleizeana apresenta um cunho político-social e estético - como nos textos rimbaudianos, em que a revolta social e a estética caminham juntas - que o conduz a abordar, no seio de sua prática estética, alguns temas políticos ocorridos nos últimos anos na França, como os protestos operários desencadeados na cidade de Tarnac, em 2008 - citados em Léman (1990) e desenvolvidos em Tarnac (2011) -, bem como seu empreendimento iconoclasta que se opõe aos mecanismos de poder da sociedade midiática tecnológica.

Aliando o projeto social ao estético, Gleize, na sequência de Rimbaud, nega os "monumentos de superstição" e busca uma linguagem que se reduz à "mais simples expressão", que equivale no contexto poético contemporâneo à linguagem literal:

Oui, très proches, ces phrases sans phrases, ces phrases aussi nues que possible, de ce que pour moi, devaient ensuite représenter les pratiques et les objets de l'art: rien qui s'impose comme "monumental", ou chargé de sens, d'un poids de sens, rien qui appelle à la vénération fascinée, à la pose, à la récitation idiote, à l'enjolivement, au cosmétique, au costume. Rien de ces superstitions. Rien que matière et langue, et forme, chiffres et traits, et lettres [...]. (GLEIZE, 2009, p. 23, grifos nossos)

Gleize assume um posicionamento estético frente à linguagem e à tradição literária, posicionamento até certo ponto militante, porque lega à arte e à poesia uma função de renovação das formas. Portanto, o pós-poeta se situa em relação à tradição literária como um opositor da linguagem e do estilo poético, enfim, do lirismo, direcionando-se para um minimalismo que prima pelos elementos mínimos portadores de sentido, os 
signos e em particular seus componentes significantes, as letras, os traços, os números, a linguagem reduzida a sua materialidade. Neste aspecto, Russo (2007, p.463) ressalta a importância para Gleize de posicionar seu empreendimento estético frente à língua e a sua tradição literária: "en tant qu'écrivain français du vingt-et-unième siècle, obligé de négocier avec l'héritage littéraire du dix-neuvième et du vingtième siècles".

Desta forma, Gleize retoma as cartas ditas "Cartas do Vidente", especialmente a que Rimbaud endereça em 13 de maio de 1871 ao professor George Izambard, onde menciona o termo "poesia objetiva" como contraponto à "poesia subjetiva". Rimbaud entende por poesia subjetiva o lirismo romântico que se deixa levar pelo pathos, abusando do estilo grandiloquente, da sublimação da realidade e da metafísica da transcendência, mas também do lirismo como expressão de um "eu" ou de uma persona em que identidade e interioridade se equivalem. Na carta a Paul Demeny, de 15 de maio, não cita explicitamente a possibilidade de construção de uma poesia objetiva, mas se refere a ela de maneira indireta ao longo do desenvolvimento de suas ideias, quando toca no tema que vincula poesia e ação. De sua releitura, Gleize depreende que a poesia objetiva, "si poésie objective il y a, est ou sera, de nouveau, en prise avec la réalité de l'histoire, [...] sera une forme de l'action, action indirecte ou restreinte, pour agir sur la langue, sur la représentation des choses [...]" (GLEIZE, 2009, p. 115, grifos nossos). A poesia objetiva se torna um gesto, uma prática, ou uma ação prática, que apresenta uma função político-social e estética. Agir sobre a língua implica, no contexto de Gleize, retirar do enunciado a ornamentação metafórica e a excessiva musicalidade que afastam da representação da realidade objetiva e sensível em prol da transmutação da realidade, que impede a adoção de uma postura crítica frente ao contemporâneo. Agir sobre a representação das coisas no interior da linguagem remete tanto à apresentação do real, focalizando as coisas em si em detrimento da subjetividade, quanto à utilização dos mecanismos de montagem que são passíveis de construir versões do real, que impedem a manipulação dos filtros midiáticos que distorcem ou "maquiam" a realidade.

Dando continuidade à tradição da ruptura, a literalidade gleizeana pode ser caracterizada a partir do título do ensaio A noir, poésie et littéralité (1992), pois de acordo com o autor, esta se relaciona à letra "a", o ser literal da literatura que reenvia à primeira letra do alfabeto por meio da qual a escrita literária se inicia em um começo-recomeço indeterminado, 
antes da concepção do sentido. O título À noir é uma referência ao soneto "Voyelles" de Rimbaud, recuperado pelo autor contemporâneo como uma representação do trabalho da escrita poética literal. O pós-poeta assinala, neste poema, uma tensão que acredita estar no centro da escrita rimbaudiana entre, os primeiros elementos da linguagem, as vogais que, enquanto letras, são partículas elementares incorporadas aos elementos reais, e o apelo a um sentido metafísico: do polo da literalidade, "A negro", ao polo do sentido ou do absoluto metafísico, que corresponde, para o póspoeta, à poesia, "O azul" (GLEIZE, 2009, p. 80). O autor contemporâneo analisa esta tensão como uma contradição entre literalidade e sentido, tomando, portanto o partido do "A negro", qualificando o poema rimbaudiano de "manifesto literalista-objetivista", pois associa cada letra às formas e às coisas do mundo (GLEIZE, 2009, p. 119).

Em uma concepção poética mais particular, Gleize (1997, p.23) afirma em Altitude zéro que escolheu o título $A$ noir para indicar que concebe a poesia "nécessairement soumise à l'obscurité, au noir matriciel [...]". O autor entende a escrita como um "travail au noir", em que o negro exprime a obscuridade do começo - momento até mesmo anterior à escrita, quando os signos não foram ainda depositados na página -, que perdura durante todo o processo de escrita, porque este trabalho se baseia na ignorância do que venha a ser a poesia: "Reste pour nous: la poésie. L'ignorance de ce qu'elle est. La faire, l'écrire, 'pour savoir'. Pour progresser dans cette ignorance. Pour savoir cette ignorance. Pour l'élucider" (GLEIZE, 1992, p.11). O ato, a ação ou a experimentação escrita torna-se uma maneira de investigar e elucidar essa ignorância. Em Le principe de nudité intégrale (1995), o pós-poeta esclarece: "de toute façon au début, il y a le noir. Le noir au commencement. Le noir du commencement. Donc, pas de récit (ou grande phrase, ou phrase de phrases). Il n'y a que: le présent aveuglé, aveuglant" (GLEIZE, 2010, p.130). Esta obscuridade do princípio no presente de sua presença remete, na prosa em prosa Néon (2004), ao começo da vida, ao nascimento de um ser ainda não totalmente definido em suas formas físicas, mas já ocupando um lugar no real: «il est de douze à quinze centimètres, de cent à 125 grammes, peut-être, un mois plus tard le double, et le double encore, on voit le sexe, les traits du visage sont dessinés, les téguments minces-transparents-rosés, les ongles, fontanelles et sutures, [...]" (GLEIZE, 2004a, p.13). A indefinição do ser reflete o trabalho de escrita da obra gleizeana, que desde os primeiros signos inscritos não 
apresenta um formato definido, porque é uma escrita que busca suas formas na objetividade de uma linguagem que diz o real. Ainda em Néon, o pós-poeta questiona: «La réalité est-elle cette totalité de signes noirs?" (GLEIZE, 2004a, p.11). A escrita gleizeana toma partido do "literalobjetivo", pois visa dizer diretamente o real, as circunstâncias reais, "du réel rugueux à étreindre", como lembra Gleize (2009, p.43) relendo Rimbaud. O negro dos "chiens noirs de la prose" se opõe "à n'importe quel bleu", uma vez que não se refere à transcendência, mas é "le noir de jais", pedra em sua forma mineral bruta, em sua realidade integral e primitiva, como os signos negros literais da prosa em prosa gleizeana: "Un noir de source. C'est un noir de fond ou de base, minéral-atlantique [...]. Un noir de prose. Le noir des chiens noirs de la prose" (GLEIZE, 1999 , p. 38). A pós-poesia transforma-se no princípio de um trabalho de investigação-elucidação "às cegas", isto é, na obscuridade ou no negro, que se inicia em um livro e se desenrola por vários livros ou se restringe a uma mesma obra, mas sempre em uma escrita cada vez mais simplificada, porque a partir do literal todas as experimentações e construções com a linguagem são possíveis. Segundo Thomas (2007, p.217), não existe nos escritos de Gleize "aucun refus principiel du mystère; bien au contraire, le mystère du réel constitue l'espace matriciel de sa réflexion poétique".

Ainda pela releitura da obra rimbaudiana, Gleize aponta a contradição entre literalidade e sentido em alguns poemas de Illuminations, como "Après le déluge" e "Aube", concluindo que existe no interior dos poemas do poeta da modernidade uma tensão entre a aspiração em conhecer o desconhecido, ligada ao projeto de vidência, e o projeto de constituir uma poesia objetiva; portanto, "d'un côté, la réinvention de la langue ou l'invention d' 'une' langue [...] 'alchimie du verbe' - et, d'un autre côté, parallèlement, travail sur soi, ascèse, dérèglement raisonné et systématique de tous les sens" (GLEIZE, 2009, p.117, grifo nosso). Tal tensão conduz Rimbaud, ainda conforme Gleize, ao extremismo experimental, observado na escrita dos poemas de Illuminations. É interessante recuperar a descrição deste programa que atribui a Rimbaud, porque se notam elementos que norteiam a poética gleizeana, a criação de uma prosa que, desvinculada da sublimação da realidade, desvela o real em sua integralidade, em sua musicalidade própria, processo que se efetua pela exposição 'in-forme' da realidade, que neutraliza, por seu turno, a construção de um sentido fixo, implicando por parte do poeta 
um modo diferente de olhar e de construir, pela linguagem, o mundo que o cerca; assim, caracteriza o programa rimbaudiano:

Travailler sur soi pour se mettre en mesure de percevoir le réel-inconnu, déboucher alors sur le site d'une poésie nouvelle, poésie comme musique du réel, rythme objectif des choses, musique "inouïe" pour laquelle il faut trouver une langue, des formes, quitte à ce que ces formes soient tellement autres qu'elles n'aient plus que de loin, voire plus du tout l'apparence de la "forme vieille", de la forme poétique héritée, et donc qu'elle s'expose à paraître informe. (GLEIZE, 2009, p.117, grifo nosso)

Segundo o pós-poeta (2009, p.118), este programa coincide com o seu projeto de construir uma pós-poesia literal e réeliste, ou seja, uma prosa que não apenas se expressa por meio de uma linguagem literal, mas atua nos mecanismos de representação do real. Em Sorties, esclarece que tem necessidade de "une certaine définition minimale de la poésie comme la seule pratique verbale, littéraire, échappant (ou tendant à échapper) aux contraintes et aux dogmes de la représentation" (GLEIZE, 2009, p.43). A escrita réeliste não visa à representação do real, ou seja, não se apoia em um mecanismo mimético, pois se volta para uma exposição do real, do real circunstancial, do acontecimento real, sem o filtro das imagens alienadoras. Do ponto de vista crítico de Thomas (2007, p. 217-218),

la lecture du réel par le poète en se situant "au ras du sol", à la surface des choses sait se faite humble et se refuse l'entrée au savoir plus. La poésie, ainsi interdite de droit d'effraction au nom de la nécessité de mise en sens, se contente d'enregistrer au plus près la plasticité du réel et ainsi en préserve le mystère.

Neste sentido, a escrita gleizeana não busca nem a transcendência, nem a imanência, contentando-se em permanecer na superfície das coisas e, assim, afasta-se de qualquer possibilidade de interpretação da realidade, mostrando-a tal qual é visualizada pelo observador que, em Les chiens noirs de la prose, repete, "je recopie la vie parce que je la vois, je recopie la vie la vie parce que je la vois. Je la recopie" (GLEIZE, 1999, p.38) ou “j'utilise pour écrire les accidents du sol”' (GLEIZE, 1999, p.46). Posteriormente, explica de modo mais detalhado esta escrita que 
se mantém na superfície dos elementos do real ou do solo, da página como solo/suporte da escrita:

Il y a plusieurs fois du sol, comme s'il y avait un sol d'en dessous, ou toujours du sol sous le sol. Soit l'idée de surface, il n'y aurait pas de profondeur, mais un étagement de surfaces posées les unes sur les autres. Ainsi le sol est sur le sol, et sous le sol il y a le sol, et le sol proprement dit est invisible parce qu'il y a plusieurs fois du sol proprement dit, il n'y a ni premier sol ni première surface. [...] Il s'agit bien de s'approcher du sol, ou d'entrer, de s'introduire: je m'introduirai à proximité $d u$ sol, je fermerai les yeux pour concevoir le sol proprement dit, le sol sans couleur dans lequel je suis [...]. (GLEIZE, 1999, p.113, grifo nosso)

Gleize encontra um ponto em comum entre a poesia objetiva rimbaudiana e sua escrita réeliste, porque ambas, segundo seu pensamento crítico, buscam a apreensão do real, de um real 'in-forme', que se efetua pelo experimentalismo formal e pela saída das fronteiras da convenção poética. Convém salientar que descreve esta herança do ponto de vista de seu projeto estético, porque lega a Rimbaud o desejo de uma busca fora do cânone poético herdado, de formas e dispositivos capazes de restituir e tocar o real intraitable e infigurable. Ora, situar o trabalho de apresentação do real pelos dispositivos já aponta para os mecanismos de criação pós-poéticos. No que concerne ao projeto gleizeano, o intuito de exteriorizar o real "in-forme" está atrelado à desagregação das formas poéticas instituídas pela tradição literária pela instalação de dispositivos e também à aporia hermenêutica em que se baseia, segundo Thomas (2009, p.114), sua escrita literal: 'le 'réelisme littéral' de la post-poésie de Gleize repose sur un silence herméneutique auto-imposé qui respecte le droit au discours propre des choses. Gleize accepte sa propre incapacité heuristique et, par principe, refuse de s'engager dans une sémiophilie interprétative". Em Les chiens noirs de la prose, o enunciador copia um hipotético diálogo com o poeta objetivista italiano Edoardo Sanguinetti, em que afirma que "il faut dire le nom des choses, par exemple des arbres, et de toutes les choses dont on connaît le nom, proches ou moins proches" (GLEIZE, 1999, p.20), o que aponta para esta necessidade de romper com a interpretação metafísica ou conceitual, em prol da materialidade dos elementos e das circunstâncias. 
À medida que prima por uma prosa literal que se identifica com a errância, o pós-poeta cão negro da prosa submete sua escrita ao deslocamento ou ao movimento aleatório por entre os espaços da realidade exterior: as ruas da cidade, as paisagens naturais, os quartos de hotel ou de hospital, os corredores, as salas de espera, as sacristias etc. A meu ver, é o movimento constante dos corpos no espaço que constrói a escrita literal gleizeana, que se define, portanto, como uma escrita topográfica e cinética. O movimento corporal e espacial perpassa o conjunto das pós-poesias gleizeanas a partir de Léman, em que a morte é um movimento que invade lentamente o corpo até atingir a imobilidade; Principe de nudité intégrale acompanha o movimento de desnudamento do cadáver; em Les chiens noirs de la prose, o cadáver é conduzido para o forno crematório; em Film à venir, a prosa segue um movimento em que se converte em filme. Os "cães negros" apresentam toda uma movimentação corporal, uma performance: rolam no chão, esfregam-se, cavam buracos e caminham pela superfície do solo, porque "être-chien" é "tirer la jambe, continuer respirant le long des couloirs, en fuite, en fuite" (GLEIZE, 1999, p.78).

A movimentação corporal no espaço é, a meu ver, uma figura de escrita ligada aos elementos da realidade material e à constituição estrutural da prosa em prosas, apoiada no verbo devenir: "Le verbe devenir devient le verbe principal" (GLEIZE, 1999, p. 39). Em Les chiens noirs de la prose, a prosa se transforma em prosa em prosas e o poeta se metamorfoseia em "cão negro da prosa", fazendo com que pós-poeta e pós-poesia rompam definitivamente com a poesia.

Entretanto, a prosa em prosa cinética gleizeana encontra sua referência nas circunstâncias do mundo real, isto é, em lugares e momentos específicos. Contudo, "onde ir" ou "para onde ir" inscreve o movimento no espaço da página, que serve de suporte para o registro das perambulações do pós-poeta por entre as ruas, os becos, os corredores, o solo, os leitos, as correntezas, cercado por muros, edifícios, telas, outdoors, que devido à constituição vertical parecem mergulhá-lo dentro de ravinas, cânions e fendas que se estreitam cada vez mais ao longo do deslocamento, até se reduzirem a um ponto no espaço. Ora, os muros, os edifícios, as telas e até os outdoors, são os lugares onde a escrita se constrói ou se desconstrói, vinculando-se ao próprio espaço da página e ao movimento de inserção dos caracteres para compor a escrita ou, ainda, o movimento de leitura do texto.

Esta escrita topográfica se constrói no movimento contínuo de deslocamento do pós-poeta/“cão negro da prosa” que segue por entre 
os espaços naturais e urbanos, bem como pelo espaço da página em branco, apesar dos obstáculos verticais que encontra cada vez mais em seu caminho:

[...] on continue. L'herbe pousse. Le goudron se répand sur le sol. Les murs sont de plus en plus hauts. Les ravins de plus en plus creux. On continue, je continue, je nage dans le courant, de plus en plus vite. On continue, il faut continuer, les falaises sont à pic. Rien à faire, pas moyen de toucher les bords. Foncer dans les couloirs, les tunnels, le lit du torrent, jusqu'où. (GLEIZE, 1999, p. 11)

Estes deslocamentos têm lugar no solo, na página/solo, acompanhando e se submetendo aos "acidentes do solo", permanecendo na superfície do real, de suas circunstâncias, eventos, percepções e sensações.

Enfim, pode-se concluir que Gleize recupera e reatualiza as obras de Baudelaire e Rimbaud por meio de sua releitura com o intuito de encontrar a matéria-prima que fornece subsídios e sustentação para sua proposta estética, ao mesmo tempo em que prolonga uma tradição poética anti-lírica já estabelecida pela modernidade.

\section{Agradecimento}

Agradeço a Fundação de Amparo à Pesquisa do Estado de São Paulo (FAPESP) pelo apoio financeiro ao projeto de pesquisa no qual se insere este artigo.

\section{Referências}

BAUDELAIRE, C. Les fleurs du mal. Paris: Flammarion, 1991.

BAUDELAIRE, C. Petits poèmes en prose (Le Spleen de Paris). Paris: Pocket, 1998.

GLEIZE, J. M. Poésie et figuration. Paris: Seuil, 1983.

GLEIZE, J. M. Léman. Paris: Seuil, 1990.

GLEIZE, J. M. À noir. Poésie et littéralité. Paris: Seuil, 1992.

GLEIZE, J. M. Le principe de nudité intégrale. Paris: Seuil, 1995.

GLEIZE, J. M. Altitude zéro. Paris: Java, 1997. 
GLEIZE, J. M. Les chiens noirs de la prose. Paris: Seuil, 1999.

GLEIZE, J. M. Néon, actes et légendes. Paris: Seuil, 2004a.

GLEIZE, J. M. Film à venir. Paris: Seuil, 2007.

GLEIZE, J. M. Les chiens s'approchent, et s'éloignent. In: GLEIZE, J. M. Sorties. Paris: Questions Théoriques, 2009. p.191-208.

GLEIZE, J. M. Sorties. Paris: Questions Théoriques, 2009.

GLEIZE, J. M. Entretien avec Jean-Marie Gleize. Prétexte Hors-Série 9, 1996a. Disponível em: <http://pretexte.perso.neuf.fr/PretexteEditeur/ ancien-site/revue/bibliographie/cteurs/jean-marie-gleize.htm>. Acesso em: 23 jan. 2009.

GLEIZE, J. M. La Post-Poésie: un travail d'investigation-élucidation. Matraga, Rio de Janeiro, v.17. n. 27, p. 121-33, jul/dez. 2010.

GLEIZE, J. M. L'excès - la prose. (Exzesse - Die Prosa). Poetenladen. den, 1996b. Disponível em: <http://www.potenladen.de/lyrik-konferenzjean-marie-gleize.htm>. Acesso em: 23 jan. 2009.

GLEIZE, J. M. Tarnac, un acte préparatoire. Paris: Seuil, 2011.

RIMBAUD, A. Artur Rimbaud. Carta a George Izambard; Carta a Paul Demeny. In: CHIAMPI, I. (Coord.) Fundadores da Modernidade. São Paulo: Atica, 1991.p. 119-124.

RIMBAUD, A. Poésies. Une saison en enfer. Illuminations. Paris: Gallimard, 1984.

RUSSO, A. Donner lieu: dialogue de circonstance: Gleize/Rimbaud/ Deguy. Contemporany French and Francophone Studies, v.11, n.4, p.463-73, 2007.

THOMAS, J. J. Jean-Marie Gleize ou la poétique de l'aporie herméneutique. In: REGGIAN, C.; MAGNE, B. (Dir.). Écrire l'énigme. PUPS, 2007. Disponível em: $<$ http://www.ieeff.org/gleizeaporiehermeneutique.pdf $>$. Acesso em: 14 abr. 2013.

THOMAS, J. J. Formulations: accessibilité et ostentaion de la poésie extrême contemporaine. In: THOMAS, J. J; SCHIAVETTA, B. Forme $\&$ informe dans la création moderne et contemporaine. Cerisy-la-Salle: Noesis, 2009. p.97-137. 